\begin{tabular}{|c|c|c|}
\hline 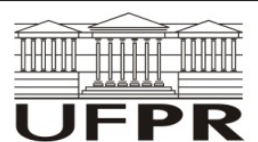 & e & $\begin{array}{r}\text { SISTEMA } \\
\text { ELETRÔNICO } \\
\text { DE REVISTAS } \\
\text { SER | UFPR }\end{array}$ \\
\hline & $\begin{array}{l}\text { DESENVOLVIMENTO } \\
\text { E MEIO AMBIENTE }\end{array}$ & www.ser.ufpr.br \\
\hline
\end{tabular}

\title{
A construção de um curso de pós-graduação interdisciplinar em Meio Ambiente e Desenvolvimento: princípios teóricos e metodológicos*
}

\author{
Magda ZANONI ${ }^{1}$, Claude RAYNAUT ${ }^{2}$, Paulo da Cunha LANA ${ }^{3}$, Dimas FLORIANI ${ }^{4}$ \\ ${ }^{1}$ Socióloga, Doutora em Sociologia do Desenvolvimento, maître de conférence da Universidade de Paris 7 Denis Diderot, França \\ ${ }^{2}$ Antropólogo, Doutor em Antropologia, directeur de recherche au Centre National de la Recherche Scientifique, Universidade de Bordeaux \\ 2 Victor Segalen, França \\ ${ }^{3}$ Biólogo, Doutor em Ciências, professor do Centro de Estudos do Mar da Universidade Federal do Paraná (UFPR) \\ ${ }^{4}$ Sociólogo, Doutor em Sociologia, professor do Departamento de Ciências Sociais da UFPR
}

Este livro recupera os principais resultados de uma iniciativa única e inovadora no que se refere à pesquisa e formação de recursos humanos na área de meio ambiente e desenvolvimento. Trata-se da experiência acadêmica e profissional vivida por docentes e discentes da primeira turma de doutorandos do curso de Meio Ambiente e Desenvolvimento da Universidade Federal do Paraná, em um processo que se desenrolou basicamente entre os anos de 1994 e 2000, com relevantes desdobramentos até os dias de hoje. Os resultados das teses individuais, articuladas em programas de pesquisa coletivos, são apresentados nos diversos capítulos, assim como o próprio processo epistemológico e metodológico de construção destes programas.

Esta apresentação tem uma tripla função. Por um lado, contextualiza esta iniciativa de formação e pesquisa no quadro mais amplo das problemáticas ambientais vividas pelo Brasil e pelo mundo como um todo, acentuando o particular papel desempenhado pela ideia da interdisciplinaridade como pré-requisito essencial para a compreensão das relações e interações entre sociedades e natureza. Por outro lado, faz um resgate histórico da construção do doutorado, enfatizando a sua estrutura pedagógica e a concepção, que sempre o norteou, de estreita ligação entre a formação acadêmica e a prática simultânea de programas de pesquisa. Por fim, mostra que estas atividades de formação e pesquisa, que contribuíram decisivamente para a própria consolidação e institucionalização do doutorado, tiveram relevantes desdobramentos acadêmicos e conceituais, através da proposição de novo programas e linhas de pesquisa, ora em curso.

\footnotetext{
* Publicado originalmente em: Raynaut, C. et al. (Eds.). Desenvolvimento e meio ambiente: em busca da interdisciplinaridade: pesquisas urbanas e rurais. Introdução. Curitiba: Ed. da UFPR, 2002. p. 9-25.
} 


\section{Princípios teóricos para uma abordagem prática da interdisciplinaridade no campo do desenvolvimento e do meio ambiente}

Hoje em dia, a comunidade científica e acadêmica passa, numa escala mundial, por um profundo movimento de interrogação sobre as modalidades de produção do saber. Tanto do lado das ciências "duras" como das ciências sociais, questionamentos surgem no tocante à definição do objeto científico, do estatuto do observador, da pertinência de um esforço para achar regularidades e limites claramente estabelecidos, dentro de um universo complexo submetido à desordem e aos efeitos determinantes de eventos inesperados. A questão da legitimidade do recorte disciplinar ocupa uma posição central nessas interrogações e a chamada para a interdisciplinaridade se expressa de modo recorrente. Contudo, esses debates permanecem em um nível principalmente teórico e traduzem mais uma reflexão sobre a filosofia das ciências do que um questionamento que possa nortear concretamente uma prática de pesquisa.

Não existe, portanto, uma definição da interdisciplinaridade que seja consensual, e menos ainda uma doutrina estabelecida que possa ser aplicada ao trabalho de campo. Torna-se, então, ainda mais importante definir com clareza as bases teóricas e metodológicas em torno das quais foram construídas as pesquisas da primeira turma do Doutorado em Meio Ambiente e Desenvolvimento da UFPR, cujos resultados são apresentados neste livro, por representarem uma etapa importante na história deste Doutorado. Estas bases foram descritas detalhadamente em artigos e textos precedentes (Doutorado em Meio Ambiente e Desenvolvimento/ UFPR, 1993; Zanoni et al., 1994; Zanoni \& Raynaut, 1994; Angulo et al., 1995; Pivot et al., 1997). Recapitularemos aqui os pontos mais importantes da postura intelectual adotada.
Interdisciplinaridade não significa acabar com as disciplinas

O desafio fundamental ao se adotar um enfoque interdisciplinar é tentar restituir, ainda que de maneira parcial, o caráter de totalidade e de complexidade do mundo real dentro do qual e sobre o qual nós todos pretendemos atuar. "Totalidade" e "complexidade" são palavras que surgem cada vez que se fala de interdisciplinaridade. O mundo real, na sua essência, é total. Ele é feito de interações múltiplas e complexas entre os muitos elementos que o compõem, não conhecendo ou admitindo fronteiras estanques. Esta totalidade do mundo, sua unicidade, as correspondências entre os elementos que o compõem constituíram um dos primeiros modos de construção da consciência do universo pelo pensamento humano e da posição do homem nele. Muitas foram e são as maneiras de afirmar e tentar apreender esta Unicidade através do pensamento mítico, das filosofias antigas e das próprias religiões, até os dias de hoje.

A novidade trazida pelo pensamento científico, quando comparado a outras formas de pensamento, foi justamente a de aceitar dividir o mundo em facetas ou níveis de organização diferentes e tentar desenvolver instrumentos específicos - conceitos, definições de objetos, métodos de observação - para tentar explicar os fenômenos observados dentro dos limites assim estabelecidos. Foi este próprio reducionismo, este esforço de abstração no próprio sentido da palavra, que possibilitou a produção de um conhecimento que permitisse uma ação mais decisiva sobre o mundo. Isto quer dizer que o recorte do real pelas disciplinas foi o movimento histórico do pensamento humano que viabilizou o surgimento e o desenvolvimento do pensamento científico. Este recorte é arbitrário, não apenas na 
medida em que segmenta uma totalidade complexa, mas também por ter nascido de um contexto cultural e socioeconômico particular, que era o da Europa pós-Renascença reatando um esforço iniciado na Antiguidade e confirmando o divórcio que vinha se estabelecendo, naquela época, entre o homem e a Natureza. É preciso, entretanto, quando se questiona o recorte das disciplinas, não esquecer que a emergência destas e a possibilidade de pensar o mundo cientificamente surgiram de um mesmo processo histórico. A característica principal do pensamento científico, quando comparado a outras formas de representação do mundo, sejam elas míticas, religiosas ou ideológicas, é a de se apoiar em instrumentos de descrição e de análise dos objetos e dos fatos que transcendem as diferenças entre as culturas e as épocas e possibilitam, ultrapassando o espaço e o tempo, um acúmulo do saber. Ele nunca se confunde com dogma, ficando sempre aberto à crítica, às dúvidas e a aprimoramentos. Por exemplo, ao contrário das cosmogonias míticas ou religiosas que apareceram ao longo da história das culturas humanas, surgindo, desaparecendo e às vezes competindo entre si, o papel da Astronomia na descrição e explicação do universo arraiga-se num antigo e contínuo movimento de controvérsias, com base em observações, experimentações e argumentos trocados, até hoje, ao longo dos séculos e das fronteiras espaciais.

No decorrer da história da construção das ciências, o problema maior reside, provavelmente, na perda da consciência do caráter formal, abstrato e potencialmente provisório desses recortes. Mais do que ângulos de representação do universo, espaços particulares nos quais os poderes da mente humana podem se exercer, o recorte disciplinar, outrora instrumento metodológico para organizar o pensamento, se transformou em partição de territórios, cada vez mais excludentes um do outro. As fronteiras disciplinares serviram para construir divisões insti- tucionais - principalmente nas universidades - que se transformaram progressivamente em redes de interações privilegiadas, quadros de afirmação de identidade intelectual e, por fim, em territórios de poder. O sistema educacional reforçou e cristalizou o que era no início uma diversidade epistemológica nas abordagens do real. Por exemplo, um aluno de medicina, de agronomia ou de engenharia sabe muito pouco ou nada, no final da sua formação, sobre as dimensões sociais dos problemas que vai enfrentar. Por outro lado, é desnecessário alunos de ciências sociais, para os quais o corpo humano ou o universo material simplesmente não existem, a não ser como objeto de modelos e representações sociais. A evolução do mundo acadêmico operou-se, em especial durante o último século, no sentido de uma crescente especialização, que tornou cada vez mais difícil a comunicação entre disciplinas. De maneira correspondente, os intercâmbios entre os grupos e os departamentos nas estruturas de ensino e de pesquisa ficaram cada vez mais esparsos ou mesmo inviabilizados.

As disciplinas, entretanto, existem. São os seus conceitos, seus métodos e suas modalidades de validação do conhecimento que constituem, até hoje, a fundamentação de nossa capacidade de conhecer o mundo, bem como de conhecer a nós mesmos. Em se tratando do Doutorado em Meio Ambiente da UFPR, falar de interdisciplinaridade não significa apelar para uma nova era do saber científico que veria o desaparecimento progressivo das fronteiras entre as disciplinas. O desejo de uma evolução radical dos modos de pensamento do mundo não é desprovido de um fundamento epistemológico. Podemos pensar, como Morin, que as barreiras entre as disciplinas e a hiperespecialização científica impedem a percepção do real na sua complexidade e na sua permanente renovação. Pensamos, no entanto, que antes de chegarmos nesse ponto, é preciso, mais 
modestamente, tentar tornar possível o diálogo e a colaboração entre as disciplinas tal como existem, sem colocar em questão logo de início suas fundamentações teóricas e metodológicas. Isto não quer dizer que a colaboração estabelecida deixará, ao final, de conduzir cada uma delas a uma evolução importante de seus procedimentos e de seus modos de produção do conhecimento.

Contudo, as pesquisas científicas não são necessariamente interdisciplinares. Em outro termos, interdisciplinaridade não deve se tornar uma nova exigência para toda e qualquer produção científica, mesmo se os modismos que afetam as instituições de pesquisa possam às vezes nos fazer pensar o contrário. Não obstante, por essencial que permaneça o enfoque disciplinar, certos objetos e certos temas necessitam uma colaboração entre diferentes disciplinas, para ser adequadamente estudados.

De onde surgem e como é que se constroem esses objetos? Sem dúvida, esta construção não pode ser feita a partir da problemática única e interna de uma dada disciplina, na medida em que a coerência de uma problemática disciplinar é dada justamente pela sua capacidade de fixar limites entre o que lhe diz respeito e o que lhe é exterior. Certamente, pesquisadores que se interessam pelas fronteiras de seu próprio campo de atuação podem sentir, como resultado do seu encaminhamento intelectual pessoal, a necessidade de chamar para si a colaboração de outras disciplinas. Isto acontece com frequência. Contudo, as lógicas que regem as instituições - e a comunidade científica não foge à regra - são geralmente refratárias à legitimação do que se situa em suas margens e muito mais favoráveis à "recentralização". Sabe-se, em particular, que os procedimentos de avaliação aplicados dentro das instituições científicas brasileiras não são em geral favoráveis às iniciativas científicas não aderentes a um dispositivo organizado em função dos recortes disciplinares (Raynaut et al., 2000).

Na prática, a identificação inicial de objetos e temas de pesquisa interdisciplinar nasce de uma relação com o mundo que não é a mesma da ciência e que não pode se satisfazer em trabalhar um segmento da realidade, isolado por razões apenas conceituais e metodológicas. Tais objetos e temas são geralmente reconhecidos a partir de uma posição social que obriga a considerar o real tal como se apresenta na experiência comum, ou seja, como um conjunto de relações que não pode ser reduzido a priori ao recorte instituído pelas disciplinas. Esta posição é, essencialmente, a da ação, a partir do momento em que se considera a necessidade desta ação ser apoiada por um conhecimento construído do campo sobre o qual ela deve ser implantada. Isto se confirma no caso de muitas operações técnicas que necessitam de vários tipos de conhecimento para serem realizadas. Torna-se ainda mais evidente quando se trata de domínios da ação onde os problemas técnicos e sociais são estreitamente interligados. Nessas circunstâncias, o esforço de análise acha-se confrontado ao mesmo tempo com as propriedades dos sistemas sociais e dos sistemas físicos e naturais. Este é o caso, em especial, das questões ligadas ao desenvolvimento e ao meio ambiente.

\section{Desenvolvimento e meio ambiente: a exigência da interdisciplinaridade e a necessidade de estudar as relações sociedade/ natureza ${ }^{1}$}

Pensar o desenvolvimento humano levando em conta suas implicações no domínio do meio

\footnotetext{
${ }^{1}$ Retomamos e desenvolvemos aqui algumas ideias já apresentadas por Raynaut e Zanoni (1994).
} 
ambiente traz necessariamente consigo a exigência da interdisciplinaridade. A própria noção de meio ambiente é extremamente complexa na medida em que é multicêntrica, aplicando-se, conforme as perspectivas adotadas, a indivíduos, grupos, organismos e populações de seres vivos. De uma representação a outra, operam-se deslocamentos de tal maneira que o que era o objeto central numa definição torna-se um elemento do meio ambiente em outra. Além disto, os processos abrangidos pela noção de meio ambiente se desenvolvem através de múltiplas escalas de espaço e tempo e movimentam uma enorme diversidade de níveis de organização. O local e o global, o instante e o tempo geológico, a molécula e o ecossistema devem, frequentemente, ser levados em conta na elaboração do modelo explicativo. Não se trata aqui apenas de diferenças formais, já que para cada nível de análise surgem propriedades que não existiam no nível inferior. Uma célula não é meramente a soma de moléculas; uma floresta se diferencia da justaposição das árvores; uma comunidade social não é a simples adição de indivíduos. Descrever e analisar essa realidade complexa implica a intervenção de várias disciplinas, atuando em vários níveis de apreensão e utilizando diversos instrumentos teóricos e conceituais.

Caso nos situemos no âmbito de uma interrogação estritamente científica, permanece possível selecionar um número limitado de níveis e ângulos de análise dentro dessa complexidade, em função dos objetivos de conhecimento perseguidos e das competências disponíveis. No entanto, quando torna-se necessário encarar os processos ambientais a partir dos seus desdobramentos concretos relacionados com a existência humana, como, por exemplo, nos casos da desertificação, chuvas ácidas ou aquecimento global, não é mais possível impor limites a priori. Torna-se imprescindível um esforço de superação das abordagens setoriais limitadas à pesquisa de causalidades lineares e reduzidas a um só nível de apreensão. Por sua própria natureza, os problemas decorrentes do campo ambiental reclamam uma abordagem que destaque as inter-relações entre fenômenos, as correspondências entre níveis de organização e a imbricação de ligações causais.

Quando se consideram não apenas as consequências de processos ambientais sobre as sociedades humanas, mas também a necessidade de incorporar as dimensões ambientais na formulação das políticas de desenvolvimento - harmonizando-se objetivos econômicos, sanitários, sociais e éticos com a preservação da natureza - a exigência de interdisciplinaridade faz-se mais presente, abrindo-se para um espaço ainda mais amplo. A colaboração entre ciências físico-naturais, disciplinas técnicas e ciências sociais torna-se absolutamente imprescindível, uma vez que se trata de analisar não somente a complexidade dos sistemas físico-naturais, mas também aquela, ainda maior, da interação entre sociedade e natureza.

Isto remete à noção do "desenvolvimento sustentável". Sem entrar aqui na indispensável discussão crítica deste conceito - que não pode ser conduzida exclusivamente em um nível especulativo, mas deve-se alimentar na análise da realidade concreta, a ser retomada na conclusão da segunda parte deste livro - reconhecemos aqui que ele coloca as relações entre as sociedades humanas e o meio físico-natural que ocupam o centro das preocupações aqui expostas. Sob este ângulo, o homem não é mais considerado como "hóspede" do meio que habita. Não é visto apenas como uma espécie viva entre outras, mas como um ser social, produtor de sentido e parte integrante desse mesmo meio do qual é, ao mesmo tempo, sujeito e objeto, ator e produto.

O meio ambiente, assim concebido, inscreve-se dentro de uma representação ampla que reúne dois subsistemas que interagem e mesmo 
comungam elementos comuns, porém, se organizam segundo propriedades estruturais e dinâmicas diferentes. O sistema Natureza compreende o conjunto de componentes biológicos e físico-químicos que interagem no interior dos grandes domínios de organização biológica, como a atmosfera, pedosfera, hidrosfera e geosfera. Este sistema Natureza integra uma parte que, embora fortemente artificializada - a ponto de ser às vezes, como na cidade, um produto direto da ação humana - não deixa de ser submetida a processos da mesma ordem dos meios físicos e naturais. Este sistema compreende certamente o homem, mas como organismo vivo, tomado individualmente ou reunido em populações. O sistema Sociedades compreende o conjunto de elementos e de processos cuja articulação participa na organização, na reprodução e na evolução das relações sociais e dos fatos culturais. Aqui, as coerências que buscamos compreender arraigam-se nos processos de produção e de circulação do sentido (representações, valores e normas), que se inscrevem na história e permanecem, em grande parte, autônomos em relação às determinações biológicas e físico-químicas. É verdade que nenhuma organização social poderia existir sem uma base material como o próprio corpo dos homens que a compõem, os bens e os objetos cuja produção, circulação e consumo permitem a sua reprodução e as técnicas necessárias à fabricação desses bens e objetos. Mas, essa base material só é considerada parte integrante do sistema Sociedades quando contribui para produzir relações sociais e fatos de cultura ou enquanto produto dessas relações e desses fatos.

A interdisciplinaridade, conforme esta perspectiva e segundo a concepção que norteou o ensino e a pesquisa da primeira turma do Doutorado, pode ser definida como a colaboração científica que há de se instaurar para estudar os objetos e as dinâmicas na interface dos dois sistemas, ou seja, no campo das inter-relações entre sistema Natureza e sistema Sociedades, no espaço onde nenhuma compreensão é possível sem o apelo simultâneo das propriedades dos dois sistemas. Este modelo paradigmático permite, ao mesmo tempo, abordar a Natureza e as Sociedades como objetos de pensamento distintos e de recusar uma visão que os opusesse como dois universos estanques.

Definir assim o campo a estudar não simplifica o quadro referencial. Acontece justamente o contrário. O espaço conceitual agora delineado apresenta-se como uma rede de interações emaranhadas entre as quais nenhuma hierarquia se impõe a priori. Para introduzir uma ordem ou uma grade de leitura dentro dessa complexidade, decidiu-se classificar as dinâmicas que animam o sistema Sociedade em quatro grandes domínios, dentro dos quais os modos de articulação entre fatos podem ser lidos em função de lógicas distintas.

- As lógicas biodemográficas: dinâmicas através das quais uma sociedade se reproduz como população de seres vivos. Isto inclui tanto os fenômenos demográficos quanto os que são ligados ao estado de saúde.

- As lógicas técnicas: que correspondem às necessidades que regem as relações entre atos técnicos, instrumentos e matéria na produção de bens e de serviços.

- As lógicas sociais e culturais: combinação de símbolos, representações, valores, normas, instituições e de relações interpessoais que orientam as ações humanas, resultando na permanência ou na mudança dos sistemas sociais.

- As lógicas do mercado: próprias às dinâmicas internas de funcionamento da forma de economia dominante em nível mundial.

Estas lógicas não remetem a distintas categorias de fatos, mas sim a eixos diferentes de leitura da mesma realidade. Assim, por exemplo, um objeto 
técnico poderá ser considerado ora em função de seus entrosamentos com outros objetos dentro de uma cadeia técnica, ora como receptáculo de representações sociais, ora como base de relações sociais de produção. Isso implica a possibilidade de fazer leituras transversais que consideram as interações entre várias lógicas. Além disto, no nível de cada um dos eixos de leitura, é possível analisar as interações específicas que se produzem com as dinâmicas dos sistemas naturais. Este quadro referencial pode ser representado como na Figura 1.

É claro que este recorte oferece uma representação simplificada e até certo ponto arbitrária da realidade. Contudo, como teremos a oportunidade de comprovar mais concretamente com a apresentação dos estudos em áreas urbanas e rurais, constituiu um referencial para estabelecer uma ponte entre o quadro teórico geral de nosso enfoque e a coleta concreta de dados pelas várias disciplinas envolvidas na pesquisa.

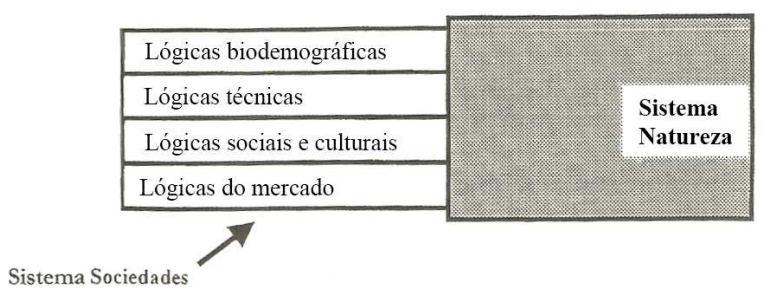

FIGURA 1 - Articulação entre lógicas dos sistemas sociais e sistema natureza

\section{A interdisciplinaridade é construída progressivamente}

Passar deste quadro conceitual para uma prática concreta de pesquisa interdisciplinar não deixa de constituir um desafio metodológico. A interdisciplinaridade não é decretada, ela se constrói. Não é por termos identificado um problema, cujo tratamento parece demandar a contribuição de várias discipli- nas, que este se constitui automaticamente em um tema de pesquisa científica. O problema não é em si uma razão suficiente para que essas disciplinas se disponham espontaneamente a colaborar. Todo um trabalho de reconstrução é necessário para passar da problemática de ação à problemática científica e para identificar as questões específicas que podem ser respondidas por cada disciplina com suas próprias competências. É preciso, também, organizar a pesquisa coletiva, definindo a maneira como vão se articular os diferentes trabalhos dos especialistas, o quadro referencial comum (em termos de amostragens, de escala de análise, de temporalidade), graças aos quais poder-se-ão reunir e confrontar os resultados que cada um obteve dentro de seu campo e com seus métodos específicos. É desejável, e habitualmente possível, que ao menos uma operação comum reúna os diferentes pesquisadores em torno de um trabalho de coleta e análise de dados.

Esses são alguns dos princípios gerais que possuem, ao mesmo tempo, uma dimensão teórica e uma dimensão prática e que desenham os contornos de uma certa concepção da interdisciplinaridade. Esta concepção inspira-se em experiências de pesquisas anteriores (Jollivet, 1992; Dobremez et al., 1990; Raynaut, 1992) mas sua prática dentro do Doutorado exigiu adaptações e permitiu renovações importantes. Por outro lado, este enfoque não é estático, mas sim destinado a evoluir, a se afirmar, a se enriquecer graças à própria experiência do Doutorado.

\section{Lições de uma experiência: a criação do Doutorado em Meio Ambiente e Desenvolvimento da Universidade Federal do Paraná}

O curso de pós-graduação em nível de doutorado "Meio Ambiente e Desenvolvimento" da 
Universidade Federal do Paraná foi resultado de um trabalho de reflexão, iniciado em 1990, no contexto da problemática meio ambiente/desenvolvimento no Brasil e em particular no Paraná. Sua instalação oficial ocorreu em setembro de 1993. Por outro lado, beneficiou-se das múltiplas reflexões e propostas já formuladas em outros países da América Latina/ Caribe, particularmente no México, Venezuela, Colômbia, Argentina e Chile, a partir da conscientização dos limites dos modelos de desenvolvimento até então implantados no continente. Por outro lado, refletiu a necessidade de uma mudança no papel da Universidade e na produção de um novo saber, induzida pela sensibilização crescente da sociedade civil, no país, à destruição dos recursos naturais, provocada pelo aspecto claramente destruidor do modelo econômico adotado durante o período da ditadura militar (1964-1985), na conjuntura eufórica do milagre brasileiro.

É necessário apresentar alguns aspectos históricos gerais da emergência da questão ambiental no país e no Estado do Paraná. Em escala nacional vários movimentos sociais surgiram em diferentes estados, oriundos dos impactos provocados, principalmente, pelo funcionamento de refinarias de petróleo, como Cubatão em São Paulo, pela construção de barragens de usinas termoelétricas, como Itaipu no Paraná e Tucuruí no Pará, pelos desmatamentos da floresta amazônica e da mata atlântica, pelo genocídio dos povos indígenas. Em um primeiro momento e de maneira informal, intelectuais, cientistas e profissionais passaram a intervir, respondendo à demanda social e colocando suas competências a serviço dos movimentos sociais e ambientais contra as grandes barragens, dos movimentos de defesa dos povos indígenas, dos seringueiros extrativistas, do movimento dos trabalhadores rurais sem terra.
A contribuição de docentes e alunos universitários assumiu múltiplas formas, expressas por estudos junto a movimentos populares, capacitação de dirigentes e militantes de movimentos, relatório de impactos ambientais, avaliação crítica das ações de desenvolvimento impostas pelo governo, produção de conhecimento para responder a problemas específicos, argumentação jurídica e difusão de informação científica, através de meios acessíveis às comunidades atingidas.

Progressivamente, a Universidade enquanto instituição foi sendo permeada por estas questões, que adquiriram uma forte dimensão social. Neste contexto, nascia uma iniciativa no seio de inúmeras universidades do país, consolidada a partir do Primeiro Seminário Nacional sobre Universidade e Meio Ambiente (Brasília, 1986). Uma das conclusões dessa reunião foi a implantação de cursos de pós-graduação em Meio Ambiente em universidades brasileiras. A partir de então, desenvolveram-se alguns fóruns de discussão permanente. Foram abordados temas de reflexão sobre a necessidade de um enfoque interdisciplinar, sobre a necessidade de novos conceitos teóricos, sobre o papel social da produção do saber, sobre conteúdo de cursos capazes de responder a tais problemáticas. Os trabalhos de seminários anuais publicados alimentaram e guiaram as discussões no seio das universidades interessadas na implantação de atividades de pesquisa, de formação e de difusão de conhecimentos na área ambiental.

No Paraná, o desmatamento de $83 \%$ da superfície de florestas, o desaparecimento das Sete Quedas de Iguaçu e a expulsão de 40.000 famílias da área de implantação da barragem de Itaipu e as ameaças de destruição dos ecossistemas de mangue e da mata atlântica, ocupados pelas tradicionais populações "caiçaras", desencadearam movimentos sociais de envergadura. Alguns optaram pela 
atribuição de terras aos agricultores, vítimas das barragens e da agricultura intensiva, responsáveis não só pelo êxodo rural, mas também pela erosão de mais de um milhão de hectares de solos nas regiões Norte e Noroeste do Estado.

O governo estadual (1983-1985) criou condições favoráveis para a elaboração de uma política ambiental (PEMA - Programa de Meio Ambiente do Estado do Paraná, 1984), reunindo várias secretarias do governo com a finalidade de promover ações que articulavam áreas da saúde, educação, agricultura, indústria, recursos naturais e recursos florestais.

A Universidade Federal do Paraná, sob a gestão do Reitor Carlos Alberto Faraco (1990-1994), não permaneceu à margem dos problemas ambientais evocados mais acima. A conjuntura nacional sensibilizou a nova direção para a proposta de um Curso de Pós-Graduação, através de um grupo de professores já engajados em atividades de formação e de difusão junto a prefeituras, associações, sindicatos e movimentos populares.

A Reitoria contribuiu durante toda a sua gestão, com as iniciativas preparatória e de implantação de um Doutorado Interdisciplinar em Meio Ambiente e Desenvolvimento, cujo fundamento consistia em uma nova abordagem dos processos de desenvolvimento, pela integração da questão ambiental e pela adoção de um enfoque metodológico interdisciplinar. Mas saliente-se que sua contribuição essencial foi a de responder à reivindicação da equipe de docentes engajados no projeto. Consolidar o enfoque interdisciplinar na formação e na pesquisa exigia que o doutorado não fosse integrado nas estruturas de departamentos da Universidade, na medida em que estes, organizados a partir de campos e objetos disciplinares, dariam uma conotação disciplinar ao Curso. Na perspectiva de criar posteriormente uma nova estrutura, adaptada ao enfoque interdisciplinar, foi concedido ao curso de pós-graduação um atribu- to particular, ou seja, sua vinculação diretamente à Pró-Reitoria de Pesquisa e Pós-Graduação.

Desde o início das discussões, em 1989, a iniciativa deu-se em estreita colaboração entre a UFPR e a Universidade de Paris 7. Organizou-se em torno do projeto de criação de um curso de pós-graduação e de um Núcleo de Pesquisa Interdisciplinar, Formação e Difusão em Meio Ambiente e Desenvolvimento (NIMAD: Núcleo Interdisciplinar de Meio Ambiente e Desenvolvimento), criado em 1989 e que deveria oferecer um quadro de colaboração aos professores da Universidade, oriundos de diferentes disciplinas e departamentos. Em 1990, foram estabelecidas colaborações através de convênios interuniversitários com a Universidade de Bordeaux 2 e com a Escola de Arquitetura Paris-la-Vilette, que, juntamente com a Universidade Paris 7, participaram regularmente das atividades de formação e de pesquisa ligadas ao projeto.

Além dos fatores referentes à conjuntura sociopolítica do país, o curso proposto também foi beneficiado por uma conjuntura excepcional, já que a proposta precedeu a Conferência das Nações Unidas sobre Meio Ambiente e Desenvolvimento, ocorrida no Rio de Janeiro em 1992. Integrou assim alguns princípios e necessidades fundamentais, ressaltados pelas discussões preparatórias e propostos na Agenda 21 que, em seu capítulo 36, convida as universidades a conduzirem os processos de promoção ou consolidação de centros de excelência nacionais ou regionais em pesquisa interdisciplinar, em relação às ciências do meio ambiente e do desenvolvimento. A constituição ou a consolidação das redes universitárias em cada país ou em nível regional deveria conduzir à promoção da pesquisa de forma cooperativa, ao intercâmbio e à difusão da informação.

Um dos principais elementos de apoio à criação de um programa de doutorado em Meio Am- 
biente e Desenvolvimento na UFPR foi a concessão, em 21 de março de 1994, de uma Cátedra UNESCO para o Desenvolvimento Sustentável. A Cátedra da UFPR compreendeu, desde a sua concepção e implantação, um conjunto de atividades de formação, de pesquisa, de informação e de documentação. No centro destas atividades estavam a valorização dos recursos naturais e a análise das dimensões econômicas, sociopolíticas e socioculturais do desenvolvimento sustentável em uma perspectiva interdisciplinar. Estes pressupostos deveriam, por sua vez, conduzir à aprendizagem de técnicas aplicáveis em distintas regiões e ao reforço das capacidades de formulação de políticas integradas de meio ambiente e desenvolvimento.

A chancela da Cátedra veio coroar, de certa forma, a criação deste curso de Pós-Graduação sensu stricto, contemplando a problemática do meio ambiente e desenvolvimento. A restrição do curso ao nível de doutorado estava intimamente ligada a uma de suas principais diretrizes conceituais. Seu objetivo primário era a construção de uma visão integrada dos problemas ambientais e das questões de desenvolvimento deles decorrentes. Seria ilusório esperar formar especialistas interdisciplinares em meio ambiente, no âmbito de programas acadêmicos limitados a uns poucos anos, que é o contexto temporal atualmente vigente no país. Este curso, tanto quanto um processo de formação acadêmica, seria também um espaço para a interação de profissionais já formados e especializados em suas respectivas áreas de conhecimento e, de preferência, já envolvidos profissionalmente com a temática do meio ambiente e desenvolvimento.

Tratando -se de uma formação doutoral, a prática da pesquisa se constituía numa dimensão fundamental dos processos de aprendizagem da interdisciplinaridade. O objetivo consistia em colocar os doutorandos numa situação que neces- sitasse a aplicação concreta dos princípios teóricos e metodológicos adquiridos na fase inicial da sua formação. Assim, no que dizia respeito à realização do seu trabalho de tese, a exigência fundamental formalizava-se por sua integração nos programas concebidos e realizados de forma coletiva, implicando interações conceituais e práticas entre especialistas de várias disciplinas. Os princípios que nortearam a implementação concreta da interdisciplinaridade e os detalhes dos procedimentos metodológicos adotados serão descritos de maneira detalhada nesta introdução e nos capítulos que seguem.

A superação das dificuldades institucionais levantadas por este desafio pedagógico deu-se., em grande parte, pelos laços estreitos criados entre docentes e pesquisadores franceses e brasileiros, em particular no quadro dos acordos CAPES-COFECUB que, a partir de 1994, permitiram a atribuição de várias bolsas e estágios a alunos brasileiros na França e alunos franceses no Brasil, além de missões de trabalho de pesquisadores de ambos os países. Além disso, e em função das exigências de competência de um tão amplo espectro de conhecimentos, a equipe da UFPR estabeleceu colaborações com Universidades brasileiras já sensibilizadas pela problemática ambiental e com elas estabeleceu vínculos permanentes. O programa de pesquisa foi consolidado através da atribuição de financiamento ao NIMAD e ao Doutorado pelo Programa de Apoio ao Desenvolvimento Cientifico e Tecnológico (PADCT-Ciências Ambientais), permitindo a realização dos trabalhos de campo da primeira turma, concretizados em 13 teses de doutoramento. O CNPq, o Centre Nacional de la Recherche Scientifique, o Conseil Régional d'Aquitaine e o Ministério francês do Meio Ambiente contribuíram também de um modo significativo ao desenvolvimento destas pesquisas e da cooperação científica franco-brasileira. 


\section{Concepção pedagógica do Doutorado}

As considerações teóricas e metodológicas apresentadas anteriormente constituíram a base para a elaboração de uma estrutura de curso de pós-graduação em nível de Doutorado, aqui expostas em alguns de seus aspectos essenciais. Tendo por objetivo principal a construção de uma visão integrada das questões ambientais e dos processos de desenvolvimento, o curso foi visualizado, desde sua implantação, como um laboratório de reflexões teóricas e de práticas concretas de interdisciplinaridade, lastreado em amplos programas de pesquisa envolvendo as problemáticas de meio ambiente e desenvolvimento. A construção pedagógica decorrente de tal finalidade visava auxiliar os diferentes especialistas a ultrapassar os conhecimentos limitados a seu próprio campo cientifico, diante das necessidades de um novo campo, que implica a análise das interações entre os sistemas sociais e os sistemas naturais. Não se tratava, porém, de formar doutores em generalidades ou, ainda, especialistas em interdisciplinaridade. O propósito era contribuir, antes de tudo, para o desenvolvimento de uma comunidade científica específica, através da formação de pesquisadores já confirmados em suas disciplinas originais, com título de mestre ou experiência equivalente - pertencentes às ciências naturais, às ciências sociais, às ciências médicas e às tecnológicas - capazes de repensar o desenvolvimento, contemplando os desafios ambientais. Ao término desta formação, universitários, pesquisadores, profissionais de organismos públicos e não governamentais, associativos, sindicais, estariam capacitados em intervir, em diferentes níveis, nos setores de políticas científicas, de reordenamento do território, de gestão ambiental e planificação do desenvolvimento, assim como avaliar projetos e ações de desenvolvimento segundo os princípios da sustentabilidade.

As especificidades deste tipo de formação residiam:

- na organização do ensino em módulos que, obedecendo a uma certa progressão, visavam inicialmente à abertura a diferentes domínios disciplinares; em um segundo momento, à integração de diferentes domínios (ou campos) disciplinares, e, por fim, à relativização destes mesmos campos. O conjunto dos três módulos assim concebidos forneceria os elementos para a análise das problemáticas de meio ambiente e desenvolvimento, discutidas em um quarto módulo, de especialização, específico para as áreas de concentração em meio ambiente e desenvolvimento rural e meio ambiente e desenvolvimento urbano (Figura 2);

- na complementaridade ensino-pesquisa: as atividades de formação forneceriam os instrumentos conceituais e metodológicos de base para o exercício da pesquisa que, por sua vez, desempenharia a função de um laboratório em constante interação com as atividades de formação;

- na seleção dos alunos segundo critérios que integrariam uma reconhecida competência na disciplina de origem e a motivação para ultrapassar os limites de sua própria disciplina, que respeitariam uma proporcionalidade de candidatos oriundos de áreas de ciências sociais e de ciências naturais e uma proporcionalidade entre candidatos pertencentes à instituição universitária (professores e pesquisadores), aos órgãos públicos e aqueles provenientes de associações e organizações não governamentais e setores privados;

- no acompanhamento de doutorandos por um comitê de orientação multidisciplinar, com o orientador principal pertencendo à mesma disciplina do aluno, e os demais, às áreas de conhecimento complementares em função do tema escolhido; 


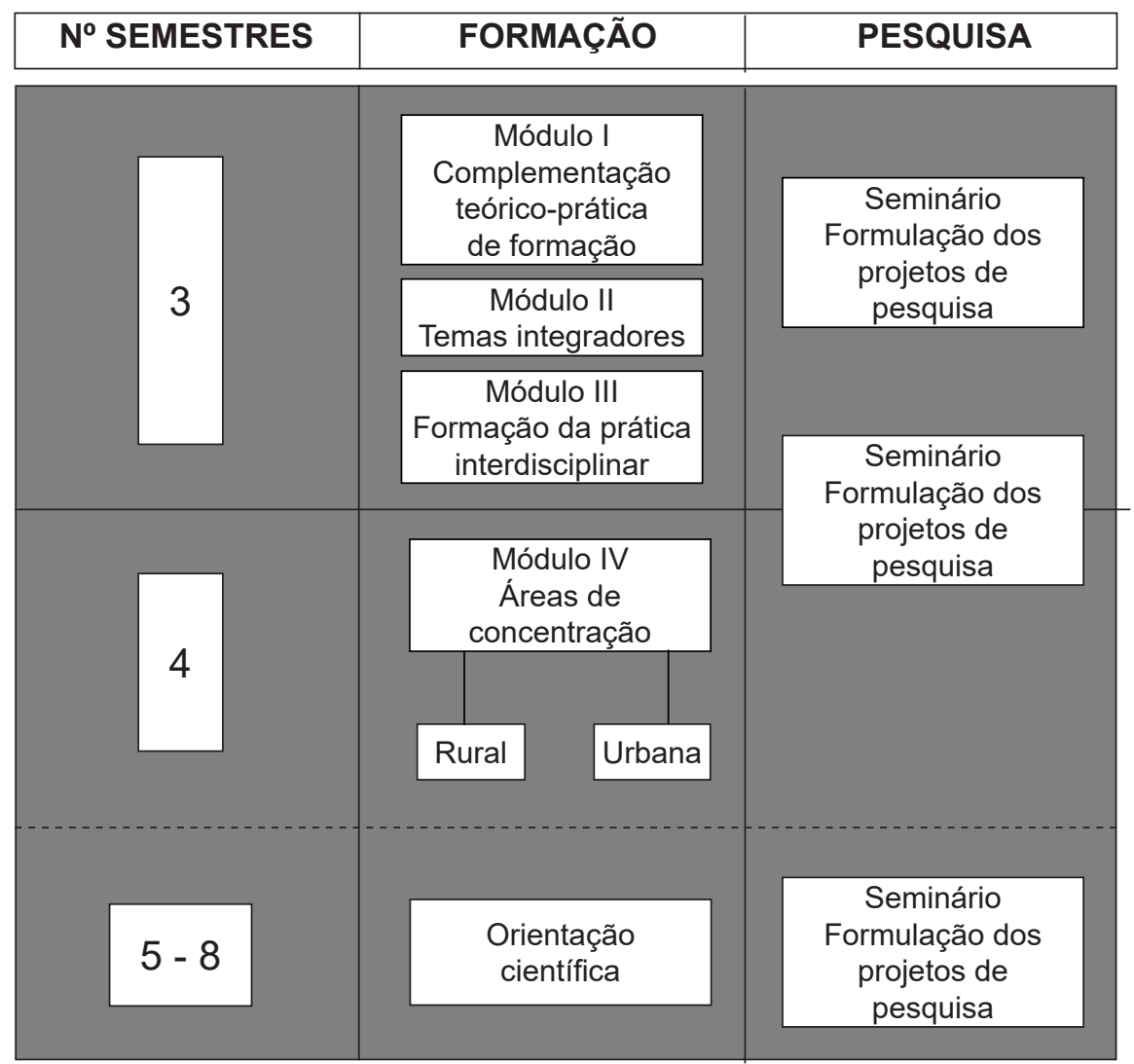

FIGURA 2 - A progressão modular em formação e pesquisa do Doutorado em Meio Ambiente e Desenvolvimento.

- na tese de doutoramento como um trabalho individual, referente à disciplina de origem do doutorando, visando, todavia, responder a uma problemática e a hipóteses formuladas em comum e refletindo um trabalho de elaboração coletivo, empreendido pelo conjunto de especialistas organizados em um mesmo grupo, com o objetivo de elaborar o quadro conceitual referente às inter-relações dos sistemas sociais e dos sistemas naturais especificas à escolha do tema e, dentro deste, do eixo de pesquisa.
A organização pedagógica do curso

Os módulos enunciados em linhas anteriores estruturaram as atividades de ensino. Os conteúdos do primeiro módulo, intitulado "Complementação teórica e prática de formação" forneceram aos doutorandos originários de diferentes áreas do conhecimento os complementos teóricos para possibilitar o diálogo com outras disciplinas. Seu conteúdo, desenvolvido sob forma de conferências e leituras orientadas, introduziu os objetos de estudo, concei- 
tos de base e métodos específicos a cada disciplina, através de seus aspectos mais dinâmicos, no intuito de ressaltar seus movimentos e transformações. $\mathrm{O}$ objetivo de tal procedimento era conscientizar os doutorandos de que, em problemáticas referentes ao campo do meio ambiente, diferentes enfoques disciplinares são necessários para sua abordagem. Esta configuração supõe uma seleção de conteúdos introdutórios, capazes de facilitar a cada especialista de uma dada disciplina a formulação de questões a especialistas de outras disciplinas, quando confrontados com a necessidade de elaboração de problemáticas comuns. Deste modo, são atingidos os objetivos de abertura, de diálogo e de comunicação.

Um segundo módulo, "Módulo integrador", visou ao conhecimento e à utilização de procedimentos integradores. Seus conteúdos foram organizados em torno de temas integradores, referentes às questões de meio ambiente e desenvolvimento e formalizados através de eixos pertinentes para conceitualizar a noção de inter-relações entre sistemas sociais e sistemas naturais:

- interações entre dinâmicas biodemográficas e dinâmicas dos ecossistemas;

- interações entre práticas materiais e dinâmicas dos ecossistemas;

- interações entre dinâmicas sociais e dinâmicas dos ecossistemas;

- interações entre mecanismos de mercado e dinâmicas dos ecossistemas;

- interações entre políticas públicas e dinâmicas dos ecossistemas.

Estes eixos, transversais às áreas de conhecimento disciplinares, permitiram a abordagem de áreas de interface entre distintas disciplinas, sendo a escolha destas condicionada às exigências específicas de cada tema integrador. A opção de variar os eixos fundamentais, que surgem através dos diferentes enfoques, dependeria de problemáticas socioeco- nômicas e culturais, ratificadas pelas dinâmicas dos sistemas naturais. Um terceiro módulo, "Formação para a prática interdisciplinar", procurou fornecer as bases teóricas e metodológicas indispensáveis para a prática da interdisciplinaridade. Sua estrutura comportava disciplinas de ordem epistemológica e de ordem instrumental. Os conteúdos de ordem epistemológica visavam à relativização dos campos disciplinares, isto é, a compreensão dos conceitos e objetos de estudo disciplinares enquanto resultado de uma construção histórica, cada disciplina sendo uma das múltiplas representações possíveis da realidade. $\mathrm{O}$ objetivo específico seria aqui repensar a produção do conhecimento. Procedeu-se a uma reflexão sobre a história das ciências (de um lado, a compreensão dos processos que conduziram à diferenciação dos campos disciplinares e, de outro, a maneira pela qual estes campos integraram os novos paradigmas a respeito da natureza) e a análise crítica dos procedimentos metodológicos disciplinares e de seus limites na abordagem dos sistemas complexos implicados nas relações sociedade-natureza. Os conteúdos de ordem instrumental procuraram fornecer os meios e instrumentos para a integração de dados complexos, heterogêneos, qualitativos e quantitativos (análise sistêmica, análise multivariada, sistema de informações geográficas), além de dar condições concretas para a prática interdisciplinar (através da organização e da definição de protocolos de trabalho, elaboração de problemática comum e a juste de escalas).

Finalmente, um quarto módulo, de especialização, pretendia fornecer os elementos para a aplicação das bases teóricas e metodológicas, dos meios e instrumentos enunciados nos módulos precedentes às problemáticas específicas do desenvolvimento sustentável, em meio rural e meio urbano. As problemáticas assim definidas levariam em conta aspectos significativos das mudanças 
desencadeadas pelo processo de desenvolvimento (polarização em um mesmo país, polarização Norte-Sul, acesso à modernidade). Considerando-se o caminho percorrido, estes conteúdos abrem perspectivas para pensar o desenvolvimento a partir de novos paradigmas.

\section{A prática da interdisciplinaridade nas pesquisas da primeira turma do Doutorado em Meio Ambiente e Desenvolvimento}

Dezesseis alunos foram selecionados em 1993 e constituíram a primeira turma. O maior desafio consistiu em passar, com eles, de uma posição de princípio, ou seja, de uma formulação conceitual, para uma aplicação concreta. Vale lembrar que esta transição se deu no quadro de um enfoque pedagógico endereçado a doutorandos vindos de diferentes horizontes, tanto no plano científico quanto no pessoal. Por outro lado, a própria equipe de docentes da UFPR provinha de vários departamentos e com o apoio de professorespesquisadores externos, constituiu-se em torno de um projeto de Doutorado, com apenas um esboço de um programa de pesquisa previamente definido. Foi preciso, então, criar desde o início, e com os alunos, o quadro dentro do qual seriam conduzidos seus trabalhos pessoais, colocando em prática a interdisciplinaridade. O método adotado para responder a esse desafio passou por uma série de etapas sucessivas.

\section{Uma área geográfica comum}

O ponto de partida do encaminhamento coletivo residiu na aceitação, por todos os estudantes, desde o processo de seleção, do princípio de compartilharem uma área de trabalho comum. O objeti- vo de toda pesquisa interdisciplinar é o de analisar as relações de determinação recíproca que podem existir entre objetos cuja identificação e observação dependem das competências específicas de diferentes disciplinas. Para poder atingi-lo, é indispensável que os questionamentos dos diferentes especialistas dirijam-se ao estudo do mesmo universo de objetos. Sem isso, será impossível entrosar as observações feitas por uns e outros e construir, além das fronteiras disciplinares, o sistema de relações que une, entre si, os objetos estudados.

Convém sermos claros a este respeito: uma reflexão teórica geral sobre a interdisciplinaridade não é necessariamente territorializada ou espacializada. Ela pode, de fato, alimentar-se de diferentes fontes de informação provenientes de domínios distintos. Por exemplo, no contexto do funcionamento dos sistemas de produção agrícola, essa reflexão pode se apoiar em dados que demonstram, num certo espaço, o peso dos fatores socioculturais; em outro caso, o das lógicas econômicas; em outro ainda, o do meio natural, e por último, o papel das práticas técnicas. Procedendo assim, poderemos colocar em evidência os impasses de um enfoque estritamente disciplinar, afinar conceitos, criticar modelos explicativos. Poderemos até formular hipóteses referentes às relações entre os diferentes determinantes do funcionamento desses sistemas. Mas, o verdadeiro desafio consiste em ir além desse nível especulativo para verificar, nos fatos, a pertinência de um tal modelo ou, em outras palavras, a possibilidade de identificar, de qualificar e às vezes de medir a relações entre variáveis que são utilizadas por disciplinas diferentes. Isso apenas pode ser realizado no âmbito de uma área geográfica comum. Sendo o objetivo do Doutorado o de criar as bases de uma prática concreta da interdisciplinaridade e de formar pesquisadores que possam colocar em prática uma convergência dos olhares, o fato de se reunirem em 
uma mesma área geográfica foi o ponto de partida do trabalho da primeira turma de alunos.

Os contornos espaciais foram primeiramente fixados de forma bastante ampla, com a proposição inicial da região litoral do Paraná, para os estudantes. Esta escolha foi guiada por uma série de argumentos que podem ser assim resumidos:

- a unidade geográfica e humana dessa região, claramente delimitada pela Serra do Mar;

- uma posição singular na história do desenvolvimento do Paraná (marginalização no decorrer do processo de modernização agrícola, aumento dos conflitos entre os objetivos de desenvolvimento e os de proteção da natureza, centrados na baía de Paranaguá e na Mata Atlântica);

- a grande diversidade de problemas que podem ser encontrados no Litoral, com concentrações urbanas (Paranaguá, cidade portuária, e balneários), coexistindo com uma pequena agricultura e pesca artesanal em curso de transformação.

No entanto, como afirmado acima, não era suficiente reunir várias disciplinas dentro de uma área comum para que as condições de uma pesquisa interdisciplinar se constituíssem espontaneamente. No espaço assim delimitado era necessário identificar temas de pesquisa que não fossem apenas pertinentes do ponto de vista científico, mas também em relação ao desenvolvimento e ao meio ambiente no contexto preciso dessa região. Todo um procedimento foi então colocado em prática a fim de construir uma problemática e programas de pesquisa que estivessem em conformidade com os problemas locais, mas que, ao mesmo tempo, pudessem servir de quadro de articulação para as teses individuais dos doutorandos.

\section{A construção da problemática - diagnóstico inicial e construção de um esquema de interações críticas}

Como mencionado anteriormente, a construção de uma problemática de pesquisa interdisciplinar realiza-se normalmente em torno de um problema concreto de desenvolvimento, cuja abordagem exige a colaboração de vários tipos de cientistas. A seleção dos especialistas que irão participar do estudo é feita em função do problema a ser estudado. No momento de criação do Doutorado, a situação era radicalmente distinta da acima preconizada. Por um lado, a composição da equipe de doutorandos e de professores foi estabelecida com a identificação ainda incipiente de um tema de pesquisa, voltado para a região litoral do Estado do Paraná. Por outro, nenhuma demanda de pesquisa havia sido feita ao Doutorado por atores de desenvolvimento, demanda que poderia ter sido assimilada e reformulada pelo próprio doutorado como programa de pesquisa.

O objetivo era, portanto, chegar a uma problemática comum que não fosse um agrupamento artificial de interesses e de posições teóricas dos estudantes e dos professores, mas que levasse em conta alguns problemas importantes referentes ao meio ambiente e o desenvolvimento na área de estudo escolhida. A etapa inicial do processo consistiu então em conduzir os pesquisadores a identificar os problemas da região litoral do Paraná. Isto foi feito a partir de uma metodologia comum de coleta de dados que, apesar de não ter sido apoiada em hipóteses de trabalho claramente formuladas, foi organizada de forma a permitir a identificação da existência de situações de tensão e de crise nas relações entre as comunidades locais e o meio onde vivem e produzem.

Esta coleta preliminar de dados foi realizada a partir de uma "grade", que remete às grandes lógi- 
cas em função das quais foi organizada a reflexão teórica sobre as relações entre sistemas sociais e sistemas naturais (vide acima). Indicadores foram escolhidos para cada um desses eixos de coleta de dados. A região litoral foi dividida em duas grandes áreas, os meios rurais e estuarinos, de um lado, e o meio urbano de outro. O grupo de doutorandos foi dividido em duas equipes distintas, trabalhando cada uma sobre uma ou outra dessas duas grandes áreas, com a coleta de dados conduzida de uma maneira metódica, mas também com a consulta a "fontes vivas", por meio de entrevistas com pessoas chave, que tinham um bom conhecimento da realidade do litoral. Nas duas áreas de estudo, foi adotada a cartografia a fim de representar os dados coletados sob uma forma que pudesse permitir a confrontação e a combinação das informações obtidas. Não detalharemos aqui esta metodologia, apresentada em vários dos capítulos a seguir. Limitamo-nos em ressaltar aqui a importância que teve essa etapa de "diagnóstico", que permitiu ao mesmo tempo organizar o diálogo entre as disciplinas, construir um referencial comum para descrever a realidade estudada e, por fim, identificar questões de pesquisa pertinentes.

Tendo-se chegado assim a uma visão organizada das relações entre as sociedades litorâneas e o meio ambiente que ocupam e exploram, a etapa seguinte foi a da construção de modelos que resumissem de maneira sintética as principais inter-relações entre fatos naturais e fatos sociais, articulando-os nos níveis da realidade litorânea e dos fatores exteriores que a influenciam. Esses modelos - também detalhados mais adiante neste livro - serviram de base de discussão para efetuar as escolhas e estabelecer as prioridades com vistas à elaboração de um programa de pesquisa. Dois programas foram assim elaborados. Eles são apresentados nos capítulos introdutórios das duas partes deste livro.
O processo de construção dos modelos foi organizado em torno de dois objetivos:

- hierarquizar e articular alguns dos problemas identificados em um corpo coerente de questões e hipóteses, tendo ligação com a problemática do desenvolvimento e do meio ambiente no litoral;

- permitir aos doutorandos trabalharem sobre uma temática de tese que correspondesse aos seus centros de interesse e às suas competências. Com isto, cada tese, sem deixar de ser obra individual, era também elemento que constituía um empreendimento científico comum.

É claro que o encaminhamento adotado para a definição dos temas de tese e para a realização das pesquisas, tal como resumido aqui, não se coadunava aos padrões acadêmicos habituais, gerando tensões e angústias entre os próprios alunos. Este procedimento impunha uma interdisciplinaridade concreta, posta em prática mediante um trabalho de equipe e não apenas como mera recuperação, no quadro de uma atuação individual, de alguns conceitos e métodos oriundos de vários campos disciplinares. Houve alunos que não conseguiram se inserir de maneira adequada dentro desse processo de pesquisa. Em geral, afastaram-se progressivamente da linha de trabalho comum e, apesar de terem aproveitado até um certo nível esta dinâmica coletiva, acabaram adotando, nas suas pesquisas pessoais, um enfoque mais individual. Circunstâncias ou eventos de caráter pessoal fizeram também com que três alunos, de um grupo original de dezesseis, desistissem do Doutorado e não levassem a cabo suas teses. Talvez por ter-se constituído em torno de um espaço mais claramente definido e de uma problemática mais restrita, o grupo que trabalhava as questões relacionadas com o meio urbano conseguiu manter uma melhor coerência do que o que se dedicava ao meio rural.

$\mathrm{Na}$ medida em que foram selecionadas para publicação, neste livro, apenas as pesquisas que 
mantiveram até o final a coerência de um processo coletivo, essa diferença se reflete no desequilíbrio entre as duas partes, com a parte do urbano resgatando os resultados de cinco teses e a do rural, de apenas duas. Não obstante, os dois programas representaram um avanço significativo, tanto do ponto de vista da prática interdisciplinar - evidenciando-se que não se trata de uma utopia, mas sim de um objetivo que pode ser alcançado - quanto de uma rica e útil contribuição ao conhecimento da realidade do litoral.

\section{Desdobramentos conceituais e metodológicos da experiência interdisciplinar do Doutorado em Meio Ambiente da UFPR}

As seções anteriores e os capítulos que se seguem descrevem, em detalhe, os antecedentes e os principais resultados de um programa de pesquisas em torno do qual se estruturou, por sua vez, uma experiência pedagógica inovadora e absolutamente atípica no quadro de formação em pós-graduação no Brasil. É essencial esclarecer, desde já, que estas atividades de ensino e pesquisa tiveram uma natural continuidade, não se esgotando nos avanços apresentados neste livro. Pelo contrário, a experiência aqui narrada foi a base ou ponto de partida para muitos dos desdobramentos conceituais, metodológicos e pedagógicos ainda hoje (abril de 2002) vivenciados pelo Doutorado em Meio Ambiente e Desenvolvimento da Universidade Federal do Paraná.

Floriani (1996) apresentou uma primeira avaliação dos desdobramentos institucionais desta experiência interdisciplinar. Mostrou a continuidade da ideia de recorte espacial como elemento nucleador da seleção da segunda turma do doutorado, com o enfoque temático centrado na Região Metropolitana de Curitiba. Os resultados desta segunda experiência estão por sua vez descritos em livro coordenado por Mendonça (no prelo).

Floriani (1996) descreveu ainda o gradual mecanismo de transição dos recortes espaciais para enfoques temáticos, de natureza transversal, como o de "Sustentabilidade: racionalidades, práticas e conflitos na gestão ambiental", adotado para a terceira turma, com a correspondente incorporação de outros procedimentos metodológicos de pesquisa e de tratamento do material empírico.

Por fim, estes programas únicos foram substituídos, já nos processos seletivos da quarta (1999) e quinta turmas (2001), por quatro linhas de pesquisa, institucionalizadas no programa de doutorado, como fruto dos próprios avanços e acúmulo destas experiências pioneiras: 1) Sistemas sociais, técnicos e recursos naturais de áreas rurais; 2) Dinâmicas naturais dos ambientes costeiros do Paraná: usos e conflitos; 3) Condições e qualidade de vida na cidade; 4) Teoria e metodologia sobre desenvolvimento e meio ambiente.

Além destes desdobramentos acadêmicos, é preciso ainda reconhecer que a implantação de programas de formação interdisciplinar na área do meio ambiente e desenvolvimento, entre os quais se inclui o da UFPR, forçou uma correspondente mudança nos próprios processos de avaliação da pós-graduação no país, particularmente pela CAPES e pelo CNPq. Até muito recentemente, estas agências de fomento vinham tratando e avaliando as questões ambientais através de seus comitês da área ecológica, ou mais raramente, das ciências sociais. Este processo, descrito por Raynaut et al. (2000), causava uma frequente e desnecessária penalização de propostas de formação interdisciplinar, avaliadas sob a ótica bem-intencionada, mas limitada, de visões disciplinares naturalistas ou sociopolíticas. 
A existência de programas multidisciplinares e interdisciplinares de formação, disseminados de norte a sul do país, fez com que estas agências modificassem seus próprios processos de avaliação, com a criação de comitês específicos e a adoção de formas de acompanhamento e avaliação de desempenho mais coerentes e compatíveis com a estrutura e prática interdisciplinar.

Os resultados das pesquisas conduzidas no meio urbano e no meio rural, tais como apresentados nas teses defendidas em 1998 e 1999, serviram de base para a elaboração de novos programas de

\section{Referências}

Angulo, R.; Lana, P. C.; Raynaut, C.; Zanoni, M. Programa de Doutorado em Meio Ambiente e Desenvolvimento da Universidade Federal do Paraná. Primeiras Jornadas Científicas sobre o Meio Ambiente. Associación de Universidades, Grupo Montevideo, 1995.

Dobremez, J. F.; Jollivet, M.; Hubert, B.; Raynaut, C. Pour une pratique de l'interdisciplinarité. Paris: CNRS (mimeografado), 1990.

Doutorado em Meio Ambiente e Desenvolvimento/UFPR, Universidades de Paris 7 e Bordeaux 2. Projeto de formação Doutoral em Meio Ambiente e Desenvolvimento. Relatório apresentado à CAPES e ao COFECUB, 1993.

Jollivet, M. (Dir.). Sciences de la Nature, Sciences de la Société. Les passeurs de frontières. Paris: CNRS, 1992.

Pivot, A.; Zanoni, M.; Raynaut, C.; Vargas, M. About Interdisciplinary Research in the Field of Environment in France and Brazil. First European Dialogue Conference for a Sustainable Society. Dinamarca: Roskild University, 1997. pesquisa que vêm sendo desenvolvidos na continuação desses trabalhos iniciais. No meio rural destaca-se o programa "Desenvolvimento sustentável e preservação da natureza em Áreas de Proteção Ambiental: permanência e mudança nos domínios social e natural (caso do Litoral norte do Paraná)", conduzido com o apoio do CNRS (França), através de seu programa "Environnement, Vie, Sociétés". No meio urbano, destaca-se o programa "Espaço urbano, situações de vida e saúde", com uma série de pesquisas conduzidas no quadro de uma cooperação científica entre o CNRS e o CNPq (Programa PICS).

Raynaut, C. (Dir.). Approches sociales de l'alimentation infantile en milieu urbain africain. Guide méthodologique. In: L'Enfant en milieu tropical, n. 201, CIE, 73 p.

Raynaut, C.; Lana, P. C.; Zanoni, M. Pesquisa e formação na área do meio ambiente e desenvolvimento: novos quadros de pensamento, novas formas de avaliação. Desenvolvimento e Meio Ambiente, 1, 71-81, 2000.

Zanoni, M.; Raynaut, C. Meio ambiente e Desenvolvimento: imperativos para a pesquisa e a formação. Reflexões em torno do doutorado da UFPR. Cadernos de Desenvolvimento e Meio Ambiente, n. 1, Curitiba, 1994.

Zanoni, M.; Angulo, R.; Lana, P. C.; Raynaut, C. Programme de recherche et de formation doctorale en environnement et développement (UFPR, Bordeaux2 et Paris 7): Fondements théoriques et méthodologiques. In: Actes des Journées du Programme Environnement $\mathrm{d} u$ CNRS. Montpellier, 1994. 